\title{
Ascending thoracic aortic aneurysm growth is minimal at sizes that do not meet criteria for surgical repair
}

\author{
Arushi Gulati ${ }^{1 \#}$, Joseph Leach ${ }^{2 \#}$, Zhongjie Wang ${ }^{1 \wedge}$, Yue Xuan², Michael D. Hope ${ }^{1}$, David A. Saloner ${ }^{2}$, \\ Liang Ge ${ }^{1}$, Elaine E. Tseng ${ }^{1}$ \\ ${ }^{1}$ Division of Adult Cardiothoracic Surgery, Department of Surgery, University of California San Francisco Medical Center and San Francisco VA \\ Medical Center, San Francisco, CA, USA; ${ }^{2}$ Department of Radiology, University of California San Francisco Medical Center and San Francisco VA \\ Medical Center, San Francisco, CA, USA
}

Contributions: (I) Conception and design: L Ge, EE Tseng; (II) Administrative support: Z Wang, Y Xuan, MD Hope, DA Saloner, L Ge, EE Tseng; (III) Provision of study materials or patients: Z Wang, Y Xuan, MD Hope, DA Saloner, L Ge, EE Tseng; (IV) Collection and assembly of data: A Gulati, J Leach, MD Hope, Z Wang; (V) Data analysis and interpretation: A Gulati, J Leach, L Ge, EE Tseng; (VI) Manuscript writing: All authors; (VII) Final approval of manuscript: All authors.

"These authors contributed equally to this work.

Correspondence to: Elaine E. Tseng, MD. Professor of Surgery, Division of Adult Cardiothoracic Surgery, University of California San Francisco Medical Center, and Chief of Cardiothoracic Surgery, San Francisco Veterans Affairs Medical Center, 500 Parnassus Avenue, Suite W405, Box 0118, San Francisco, CA, USA. Email: elaine.tseng@ucsf.edu.

Background: Historic studies of nonsyndromic ascending thoracic aortic aneurysms (aTAAs) reported that the typical aTAA growth rate was approximately $0.6 \mathrm{~mm} / \mathrm{year}$, but data were limited due to relatively few studies using computed tomography (CT) imaging. Our purpose was to reevaluate the annual growth rate of nonsyndromic aTAAs that do not meet criteria for surgical repair in veterans in the contemporary era, using modern CT imaging suitable for highly accurate and reproducible aneurysm measurement.

Methods: Nonsurgical patients (diameter $<5.5 \mathrm{~cm}$ ) undergoing aneurysm surveillance at a Veterans Affairs Medical Center with repeat CT imaging performed 3 to 5 years apart were identified. Maximum diameter was determined by a single radiologist using multiplanar reformat-based measurements. Average rate of aneurysm growth was evaluated based on longest available follow-up.

Results: Sixty-seven patients were included. Average follow-up time was $4.06 \pm 0.83$ years. Patients were exclusively male, with average age of $68.1 \pm 6.0$ years, and the majority had a history of smoking $(\mathrm{n}=52,78 \%)$, hypertension ( $\mathrm{n}=52,78 \%$ ), and dyslipidemia $(\mathrm{n}=48,72 \%)$. Average baseline aneurysm diameter was $44.0 \pm 3.2 \mathrm{~mm}$ and average growth rate was $0.11 \pm 0.31 \mathrm{~mm} /$ year, with no difference in growth rate between patients with initial diameter $\leq 45 v s$. $>45 \mathrm{~mm}$. Only 3 patients experienced clinically significant changes in diameter with magnitude greater than $5 \%$ of baseline.

Conclusions: In this veteran population, most patients did not experience significant annual aneurysm growth over up to 5 years of follow-up, regardless of initial diameter. Thus, in the modern era, aTAAs may not grow as quickly as previously described, which will be important in determining appropriate intervals for aneurysm surveillance based upon risk-benefit ratio.

Keywords: Aortic aneurysms; type A dissection; diameter; growth

Submitted Jan 14, 2021. Accepted for publication Jun 17, 2021.

doi: $10.21037 /$ qims-21-55

View this article at: https://dx.doi.org/10.21037/qims-21-55

^ ORCID: 0000-0001-5356-6778. 


\section{Introduction}

Most ascending thoracic aortic aneurysms (aTAAs) are asymptomatic until sudden rupture or dissection, at which point they are often fatal. Patients with acute type A dissection (ATAD) of the ascending aorta experience preoperative mortality rates of $40 \%$, and those that do receive surgery have an in-hospital mortality rate of $12-25 \%$ and a 5 -year mortality rate of 30-50\% (1-3). Patients with rupture experience similarly high, if not higher, mortality rates $(1,4)$.

The current American College of Cardiology/American Heart Association (AHA) guidelines use ascending aortic diameter as the primary determinant of risk in aTAA patients. Surgery is recommended when aortic diameter exceeds $5.5 \mathrm{~cm}$, in the absence of rapid growth, clinical symptoms, or a history of a connective tissue disorder (1). However, a majority $(50-87 \%)$ of patients presenting with ATAD have an aortic diameter of $<5.5 \mathrm{~cm}$, indicating that there is a need for a more comprehensive risk-stratification than diameter alone $(5,6)$. To this end, guidelines recommend rapid expansion as another criterion for elective aTAA repair, defined as growth greater than $0.5 \mathrm{~cm} /$ year. Diameter growth rate, which is governed by a host of biological and mechanical drivers, offers further insight into the evolution of the aneurysm compared to a static diameter measurement.

Thus, it is critical to understand how aTAA diameter changes with time to determine not only which patients meet criteria for surgery, but also which patients are at risk for exceeding the $5.5 \mathrm{~cm}$ surgical threshold over time and which patients may need more rigorous surveillance. While current guidelines offer criteria for surgical repair, there remains a lack of consensus regarding appropriate surveillance intervals of moderately sized aTAAs. Currently, the 2014 European Society of Cardiology guidelines recommend initially imaging patients with aTAA diameters $<4.5 \mathrm{~cm}$ annually and imaging patients with aTAA diameters between 4.5 and $5.5 \mathrm{~cm}$ every 6 months, regardless of valve morphology (7). However, the American Association for Thoracic Surgery (AATS) consensus guidelines provide separate and more stringent recommendations for patients with bicuspid aortic valves (BAV). These AATS guidelines recommend initial electrocardiogram (ECG)-gated computed tomography angiography (CTA) or magnetic resonance imaging (MRI) for all aTAAs between 4.0 and $5.5 \mathrm{~cm}$ every 6 months, although imaging for stable aneurysms may be spaced to every 2 or 3 years for aTAAs $<5 \mathrm{~cm}$ or to every 1 year for aTAAs between 5.0 and $5.4 \mathrm{~cm}(8)$.
Much of the clinical data regarding aneurysm growth that was used to initially inform the $5.5 \mathrm{~cm}$ surgical threshold and recommended surveillance strategies is decades old and its relevance is potentially limited by its derivation from clinically heterogenous populations using a wide variety of imaging techniques, including echocardiography $(4,9)$. The purpose of our study was to reevaluate the annual growth rate of nonsyndromic aTAAs that do not meet criteria for surgical repair in the contemporary era, using a more homogeneous population and modern imaging techniques, to help determine appropriate intervals for aneurysm surveillance.

\section{Methods}

\section{Data collection}

The study was conducted in accordance with the Declaration of Helsinki (as revised in 2013). The study was approved by the University of California San Francisco Committee on Human Research and San Francisco Veterans Affairs Medical Center (SFVAMC) Institutional Review Board (IRB 10-03594) and individual consent for this retrospective analysis was waived. Patients within the American Veterans Affairs (VA) Healthcare system are predisposed to aneurysm formation and growth due to their high prevalence of risk factors, such as smoking, hypertension, male sex, and hyperlipidemia, and represent a fairly homogeneous population in terms of these and other important clinical factors (10). Patients at SFVAMC undergoing aTAA surveillance with baseline aneurysm size $\geq 4.0 \mathrm{~cm}$ and baseline and at least one follow-up computed tomography (CT) scan taken 3-5 years after baseline were included. Only scans of the same type (i.e., contrast $v s$. non-contrast) were compared for a single patient. For patients that had more than one follow-up scan during the 5-year period, all available follow-up scans of the same type that were a minimum of 3 years after the baseline scan were included. All images were downloaded from the radiology picture archiving and communication system for review in the open-source Digital Imaging and Communications in Medicine viewer Horos (Horosproject. org, RRID:SCR_017340). Imaging was performed with or without ECG-gating, with slice thickness from 0.625 to $2.5 \mathrm{~mm}$. If an ECG-gated scan was available, images acquired during the diastolic phase of the cardiac cycle were reviewed. Assessments of aTAA size were then made using a double-oblique technique to measure the greatest aortic 
Table 1 Demographics of 67 patients with ascending thoracic aortic aneurysms

\begin{tabular}{|c|c|}
\hline Characteristic & Number [\%] \\
\hline Age (years, mean \pm SD) & $68.1 \pm 6.0$ \\
\hline \multicolumn{2}{|l|}{ Sex } \\
\hline Male & $67[100]$ \\
\hline \multicolumn{2}{|l|}{ Race } \\
\hline Caucasian & $52[78]$ \\
\hline African American & 6 [9] \\
\hline Alaska Native or Native American & $3[4]$ \\
\hline Other & $1[1]$ \\
\hline Unknown & $5[7]$ \\
\hline $\mathrm{BMI}\left(\mathrm{kg} / \mathrm{m}^{2}\right.$, mean $\left.\pm \mathrm{SD}\right)$ & $30.3 \pm 5.5$ \\
\hline $\mathrm{BSA}\left(\mathrm{m}^{2}\right.$, mean $\left.\pm \mathrm{SD}\right)$ & $1.8 \pm 0.3$ \\
\hline Smoking history & $52[78]$ \\
\hline \multicolumn{2}{|l|}{ Medical comorbidities } \\
\hline Hypertension & $52[78]$ \\
\hline Hyperlipidemia & 48 [72] \\
\hline Diabetes & $11[16]$ \\
\hline COPD & 17 [25] \\
\hline \multicolumn{2}{|l|}{ Valvular pathology } \\
\hline Bicuspid aortic valve & $5[7]$ \\
\hline Aortic insufficiency & 28 [42] \\
\hline Trace & $12[18]$ \\
\hline Mild & $13[19]$ \\
\hline Moderate & 2 [3] \\
\hline Severe & $1[1]$ \\
\hline Aortic stenosis & $6[9]$ \\
\hline Family history of aneurysm & 9 [13] \\
\hline
\end{tabular}

$\mathrm{SD}$, standard deviation; BMI, body mass index; BSA, body surface area; COPD, chronic obstructive pulmonary disease.

diameter in a plane normal to the local vessel centerline (11). All measurements of the ascending aorta were made between the sinotubular junction and aortic arch at the level of the innominate artery, and patients with aortic root aneurysms were excluded. For CTA images, only aortic luminal diameter was measured, while for non-contrast CT images, aortic wall thickness was also included in diameter measurements. Aortic measurements were made by a single board-certified radiologist blinded to any additional subject information. All baseline imaging was reviewed first, followed by all subsequent surveillance imaging performed at 3 , then 4 , and then up to 5 years such that no one subject's imaging was reviewed uninterrupted. Clinical variables were collected separately by another investigator using subjects' medical records. Body surface area was calculated from height and weight using the method outlined by Du Bois and Du Bois (12).

\section{Statistical analysis}

Data processing and statistical analysis were performed using R software (R Foundation for Statistical Computing, Vienna, Austria). Paired Student's $t$-tests were used to compare diameter distributions at 3, 4, and 5 years from baseline and independent Student's $t$-tests were used to compare growth rates between groups. Average growth per year was calculated using baseline and latest diameter measurements. Results with $\mathrm{P}<0.05$ were considered to be statistically significant.

\section{Results}

\section{Patient demographics and imaging characteristics}

Our cohort included 67 patients with at least 2 CT scans between 3 and 5 years apart. Sixty-one patients (91\%) had CTA imaging at baseline and throughout the followup period, while 6 patients (9\%) had non-contrast CT imaging at baseline and throughout follow-up. Twenty patients (30\%) had follow-up available up to 3 years from baseline, 25 (37\%) had follow-up available up to 4 years from baseline, and $22(33 \%)$ had follow-up available at the end of the 5 -year period. The average duration of follow-up was $4.06 \pm 0.83$ years, and patients had a median of 2 followup CT scans over this period. No patients underwent operative or endovascular aortic repair during the study period. Of the 3 patients that died during the 5 -year followup period, 2 died of cardiopulmonary causes unrelated to their aneurysm and the cause of death was unspecified for the remaining patient.

The average age of the cohort was 68.1 years, and patients were entirely from the male veteran population (Table 1). The majority of patients were Caucasian $(\mathrm{n}=52$, $78 \%)$ and had a prior smoking history $(\mathrm{n}=52,78 \%)$. The most common medical comorbidities were hyperlipidemia $(\mathrm{n}=48,72 \%)$ and hypertension $(\mathrm{n}=52,78 \%)$. Of the 52 
Table 2 Comparison of aneurysm diameters at 3-, 4-, and 5-year follow-up to paired baseline data

\begin{tabular}{lccc}
\hline Time point $^{\dagger}$ & Baseline diameter $[\mathrm{mm}$, median $(\mathrm{IQR})]$ & Follow-up diameter $[$ mm, median $($ IQR) & Significance \\
\hline 3 years $(\mathrm{n}=53)$ & $43.5(42.0-45.5)$ & $43.9(42.2-45.5)$ & \\
4 years $(\mathrm{n}=38)$ & $43.0(42.0-45.4)$ & $43.9(41.8-45.5)$ & $\mathrm{P}=0.02^{\ddagger}$ \\
5 years $(\mathrm{n}=22)$ & $45.0(42.6-47.0)$ & $45.2(43.0-48.2)$ & $P=0.33$ \\
\hline
\end{tabular}

${ }^{\dagger}$, for patients with multiple scans across the follow-up period, all available scans were compared to baseline imaging; ${ }^{\ddagger}$, values with $\mathrm{P}<0.05$ were considered statistically significant. IQR, interquartile range.

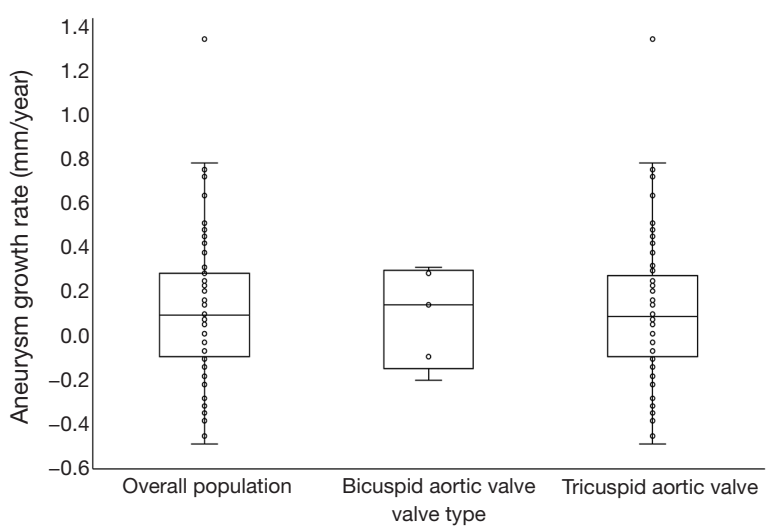

Figure 1 Comparison of average annual growth rate distributions between overall population and patients with tricuspid $v$ s. bicuspid aortic valves.

patients with hypertension, 45 (87\%) had well-controlled blood pressure at the time of their baseline imaging, defined as systolic pressure $\leq 140 \mathrm{mmHg}$ and diastolic pressure $\leq 90 \mathrm{mmHg}$ from the prior AHA definition of hypertension (13), which changed in 2017. Twenty-four patients (36\%) were prescribed an angiotensin-converting enzyme inhibitor or angiotensin II receptor blocker and 26 patients (39\%) were prescribed a beta-blocker at the time of their baseline imaging. Additionally, 5 patients had BAVs while 62 had tricuspid aortic valves (TAVs). Thirty-four patients (51\%) had aortic valve pathology, including either aortic stenosis or regurgitation.

\section{Aneurysm size and growth}

In this nonsurgical group, the average aTAA diameter at baseline was $44.0 \pm 3.2 \mathrm{~mm}$. The majority of patients $(\mathrm{n}=46$, $69 \%$ ) had a baseline diameter of $\leq 45 \mathrm{~mm}$, while 18 patients (27\%) had a baseline diameter of between 45 and $50 \mathrm{~mm}$, and 3 patients (4\%) had a baseline diameter between 50 and $55 \mathrm{~mm}$.
The difference in aneurysm diameter was statistically significant between baseline and last available followup, from $44.0 \pm 3.2$ to $44.5 \pm 3.5 \mathrm{~mm}(\mathrm{P}=0.007)$, though not clinically significant due to inability to resolve $0.5 \mathrm{~mm}$ changes in diameter practically on imaging. There was no significant difference in rate of growth between patients with contrast and non-contrast CT imaging $(\mathrm{P}=0.46)$. The overall average aneurysm growth rate was $0.11 \pm 0.31 \mathrm{~mm} /$ year and no patients met the $55 \mathrm{~mm}$ threshold for elective surgery during the study period. Differences in diameter over the follow-up period were not statistically significant for patients with total follow-up duration of $4 v s$. 5 years (Table 2).

When stratified by valve type, the average growth rate for TAV patients was $0.11 \pm 0.32 \mathrm{~mm} /$ year, while the average growth for BAV patients was $0.10 \pm 0.19 \mathrm{~mm} /$ year (Figure 1). Overall, only 3 patients, all of which had TAVs, had an increase in diameter greater than $5 \%$ of the baseline value. Forty-one patients (61\%) experienced increases in diameter over the follow-up period, at an average rate of $0.29 \mathrm{~mm} / y e a r$ for this subgroup, while 26 (39\%) experienced decreases or no change in diameter, at an average rate of $-0.18 \mathrm{~mm} /$ year. Additionally, there was no significant difference in growth rates between patients with a baseline aneurysm diameter $\leq 45$ and $>45 \mathrm{~mm}(0.09 \pm 0.32$ vs. $0.14 \pm 0.31 \mathrm{~mm} /$ year, $\mathrm{P}=0.26$ ).

\section{Discussion}

Currently, guidelines for elective surgical repair of aTAAs are based on aneurysm diameter due to prior studies of nonsyndromic aTAAs demonstrating a hinge point of $6.0 \mathrm{~cm}$, above which the risk of dissection greatly increases (14). Around this size, aortic distensibility falls and vessel wall stress rises, increasing the probability of dissection, rupture, or death from $6.5 \%$ to $14.1 \%$ per year (15).

While faster growth rates have been shown to correlate to a greater risk of dissection and rapid growth 
is also a criterion for elective aTAA surgical repair, it is unclear what the true average growth rate is in highcomorbidity populations. Reported annual aneurysm growth rates in current studies are highly variable and range from -1.0 to $1.9 \mathrm{~mm} /$ year $(16,17)$. Additionally, much of the available data regarding aneurysm growth is decades old and derived using a wide variety of imaging techniques, including echocardiography, that have now been replaced by guideline-directed CT and MR imaging $(4,9)$. Furthermore, medical management of patients who do not yet meet surgical criteria has been substantially improved over the last 20 years to potentially reduce aTAA growth, with greater emphasis on cardiovascular health and optimization of modifiable risk factors such as smoking cessation and blood pressure control (1). Therefore, we sought to characterize the annual growth rate of aTAAs in our nonsyndromic veteran population and to analyze factors associated with higher aTAA growth, using the standard-ofcare modern imaging.

One recent meta-analysis of 15 studies reported that typical aTAA growth was approximately $0.61 \mathrm{~mm} /$ year overall, and $0.31 \mathrm{~mm} /$ year for TAV patients compared to $0.76 \mathrm{~mm} /$ year for BAV patients (18). In contrast, very few patients in our cohort $(n=3)$ experienced aneurysm growth of this magnitude, and the average growth rate of $0.11 \mathrm{~mm} / \mathrm{year}$ in our cohort is substantially lower than previously reported. Furthermore, we found that BAV patients had a similar growth rate compared to TAV patients, although this finding may be affected by the small number of BAV patients in our cohort. Our aggregate findings are consistent with those of Kim et al., who found the average diameter growth rate of 40-55 mm nonsyndromic aTAAs was $0.1 \mathrm{~mm} /$ year. Kim's data was derived from study of an impressive 4,068 patients, although it was based on measurements made at transthoracic echocardiography, which has a greater degree of inter-observer variability and limited reproducibility owing to a lack of consistency in insonation angle and aneurysm measurement location over time (19). Our finding that there was no correlation of baseline diameter with growth rate is also consistent with this prior study, which found a mixed relationship between diameter and expansion rate.

Established risk factors for aTAA growth and dissection include male sex, increased waist circumference, history of smoking, and hypertension (10). Our population was fairly homogenous and consisted of only males, with a majority of patients having a BMI greater than $25 \mathrm{~kg} / \mathrm{m}^{2}$, as well as a history of smoking and hypertension. Despite the high prevalence of risk factors for aneurysm growth in our cohort, the overall aneurysm size remained very stable over 5 years, and patients with data available at both 4 and 5 years of follow-up had no significant increase in diameter between the latest time points.

The stability of aTAA diameter over time in our population may be in part due to widespread antihypertensive use for improved blood pressure control, although this is speculative. The underlying mechanism of aTAA formation is thought to be in part related to vascular inflammation and extracellular matrix degradation contributing to compromise of the medial aortic wall. Underlying aortic valve pathologies, i.e., BAV, may increase shear stresses along the aortic wall, while hypertension increases wall stress, and genetic disorders disrupt connective tissue structure to predispose patients to aTAA formation and potentially growth (20). Beta-blockers are currently considered the "gold-standard" of aTAA therapy, due to their adrenergic blockade and subsequent reduction in heart rate and aortic flow, although early trials primarily focused on these effects in patients with Marfan syndrome $(21,22)$. Studies of beta blockade in aneurysm patients without Marfan syndrome have primarily focused on abdominal aortic aneurysms, and results regarding utility of beta-blockers in reducing aneurysm diameter have been conflicting $(23,24)$. Recent clinical trials of angiotensin receptor blockers have shown promising effects on reduction in the rate of aortic root dilation in patients with Marfan syndrome, and statin therapy has also shown promise in mouse models of Marfan syndrome for reducing aneurysm growth $(25,26)$. Data on the effects of these drugs on nonsyndromic aTAA progression are limited. Although we saw high rates of use for all three of these drug classes in our study population, this study was not structured nor powered to investigate potential medication effects on aneurysm progression and it remains unclear if the utility of these medications is limited to the pathophysiology of Marfan syndrome or if they have broader utility in patients with other aortic aneurysm syndromes. Thus, there is a need for further prospective data regarding medical optimization in aTAA patients without underlying connective tissue disorders.

Currently, European guidelines recommend annual CT imaging for aTAAs $<4.5 \mathrm{~cm}$ and imaging every 6 months for aneurysms between 4.5 and $5.5 \mathrm{~cm}$ (7), while AATS guidelines for BAV patients recommend initial ECG-gated CTA or MRI for aTAAs between 4.0 and $5.5 \mathrm{~cm}$, with longterm imaging every 1 to 3 years, depending on size (8). 
However, no unified consensus guidelines currently exist for tricuspid and bicuspid valve aTAA surveillance based upon contemporary evidence, and the optimal interval for surveillance remains unclear. Imaging at more frequent intervals than necessary carries increased radiation and increases healthcare costs (27), while imaging at wider than necessary intervals carries the risk of missing patients with rapid growth. Our results demonstrate minimal aneurysm growth in a population with a higher prevalence of aneurysm risk factors than the general population and suggest that diameter-based guidelines may not provide the most specific measure of aneurysm dissection risk. Our findings suggest that alternative methods of risk stratification may be more appropriate in aTAA patients. Both we and others have previously demonstrated that aneurysm wall stress is one such indicator that should be evaluated by future randomized controlled trials $(28,29)$. Use of biomechanical markers such as aneurysm wall stress may allow for prospective identification of patients who will eventually differentiate into rapidly enlarging, dissecting, or quiescent and size-stable aneurysm phenotypes, all of which may for some time present with the moderately and stably sized type of aneurysms seen in this study. Until the biomechanical factors involved in aneurysm rupture and progression risk are better understood, our data suggest the need for randomized controlled trials to assess the safety and efficacy of increased surveillance intervals as compared to the European surveillance guidelines for moderately sized aTAAs.

\section{Limitations}

Our study is limited in that it was conducted in a veteran cohort devoid of females, and so our results may not be reflective of aTAA dynamics in women. As our veteran population had a high prevalence of smoking, hypertension, and hyperlipidemia, our results may also not be reflective of the overall civilian population. Since this study was anatomically limited to the ascending thoracic aorta, further studies are needed to assess whether similar stability is observed in high-comorbidity populations in other aortic segments, including the aortic arch and descending aorta. Furthermore, our comparisons between growth rate of BAV and TAV patients were limited by the small number of patients with bicuspid valve morphology in our study population, making it difficult to assess the importance of more frequent surveillance interval for this higher risk population.
While a small subset of our patients had non-contrast imaging, we did not mix contrast and non-contrast imaging. Therefore, while the baseline diameter of these patients and subsequent categorization may have been increased slightly due to inclusion of aortic wall thickness, we were still able to reliably detect growth rate. To avoid inter-observer variability, the official radiology reports for maximum diameters were not used in this study. Instead, a single radiologist, blinded to the patient information measured the maximum diameters in a standardized fashion, while statistical analysis was performed by the other primary author.

\section{Conclusions}

We found that in our center's cohort of male veteran patients undergoing surveillance for aTAA, there was minimal aneurysm growth between baseline and followup at 3 to 5 years despite high prevalence of multiple risk factors for aneurysm growth. Our findings suggest that rate of aneurysm growth may not be as high as previously described in the literature. Further large-scale prospective studies are needed to characterize growth rate in the larger civilian population and to identify pharmacologic and biomechanical factors that may mitigate or predict aTAA growth, respectively. These results may be used to inform more appropriate surveillance intervals in aTAA patients.

\section{Acknowledgments}

Funding: This work was supported by the National Institutes of Health (R01HL119857-01A1 to EET, LG, K25HL150408 to YX), the American Heart Association Postdoctoral Fellowship (20POST35211107 to ZW), and University of California San Francisco Summer Explore Research Fellowship (to AG).

\section{Footnote}

Conflicts of Interest: All authors have completed the ICMJE uniform disclosure form (available at https:// dx.doi.org/10.21037/qims-21-55). AG is the recipient of the University of California Summer Explore Research Fellowship; ZW is the recipient of an American Heart Association Postdoctoral Fellowship; and EET and LG are the recipients of a grant from the Marfan foundation to study aneurysms and a National Institutes of Health Grant to study ascending thoracic aortic aneurysms. The other 
authors have no conflicts of interest to disclose.

Ethical Statement: The authors are accountable for all aspects of the work in ensuring that questions related to the accuracy or integrity of any part of the work are appropriately investigated and resolved. The study was conducted in accordance with the Declaration of Helsinki (as revised in 2013). The study was approved by the University of California San Francisco Committee on Human Research and San Francisco Veterans Affairs Medical Center Institutional Review Board (IRB 10-03594) and individual consent for this retrospective analysis was waived.

Open Access Statement: This is an Open Access article distributed in accordance with the Creative Commons Attribution-NonCommercial-NoDerivs 4.0 International License (CC BY-NC-ND 4.0), which permits the noncommercial replication and distribution of the article with the strict proviso that no changes or edits are made and the original work is properly cited (including links to both the formal publication through the relevant DOI and the license). See: https://creativecommons.org/licenses/by-nc-nd/4.0/.

\section{References}

1. Hiratzka LF, Bakris GL, Beckman JA, Bersin RM, Carr VF, Casey DE Jr, et al. 2010 ACCF/AHA/AATS/ACR/ ASA/SCA/SCAI/SIR/STS/SVM Guidelines for the diagnosis and management of patients with thoracic aortic disease. A Report of the American College of Cardiology Foundation/American Heart Association Task Force on Practice Guidelines, American Association for Thoracic Surgery, American College of Radiology, American Stroke Association, Society of Cardiovascular Anesthesiologists, Society for Cardiovascular Angiography and Interventions, Society of Interventional Radiology, Society of Thoracic Surgeons, and Society for Vascular Medicine. J Am Coll Cardiol 2010;55:e27-129.

2. Parikh N, Trimarchi S, Gleason TG, Kamman AV, di Eusanio M, Myrmel T, Korach A, Maniar H, Ota T, Khoynezhad A, Montgomery DG, Desai ND, Eagle KA, Nienaber CA, Isselbacher EM, Bavaria J, Sundt TM, Patel $\mathrm{HJ}$. Changes in operative strategy for patients enrolled in the International Registry of Acute Aortic Dissection interventional cohort program. J Thorac Cardiovasc Surg 2017;153:S74-9.

3. Chiappini B, Schepens M, Tan E, Dell' Amore A, Morshuis W, Dossche K, Bergonzini M, Camurri N, Reggiani LB,
Marinelli G, Di Bartolomeo R. Early and late outcomes of acute type A aortic dissection: analysis of risk factors in 487 consecutive patients. Eur Heart J 2005;26:180-6.

4. Kuzmik GA, Sang AX, Elefteriades JA. Natural history of thoracic aortic aneurysms. J Vasc Surg 2012;56:565-71.

5. Parish LM, Gorman JH 3rd, Kahn S, Plappert T, St JohnSutton MG, Bavaria JE, Gorman RC. Aortic size in acute type A dissection: implications for preventive ascending aortic replacement. Eur J Cardiothorac Surg 2009;35:9415; discussion 945-6.

6. Kim EK, Choi SH, Sung K, Kim WS, Choe YH, Oh JK, Kim DK. Aortic diameter predicts acute type A aortic dissection in patients with Marfan syndrome but not in patients without Marfan syndrome. J Thorac Cardiovasc Surg 2014;147:1505-10.

7. Erbel R, Aboyans V, Boileau C, Bossone E, Bartolomeo RD, Eggebrecht H, et al. 2014 ESC Guidelines on the diagnosis and treatment of aortic diseases: Document covering acute and chronic aortic diseases of the thoracic and abdominal aorta of the adult. The Task Force for the Diagnosis and Treatment of Aortic Diseases of the European Society of Cardiology (ESC). Eur Heart J 2014;35:2873-926.

8. Borger MA, Fedak PWM, Stephens EH, Gleason TG, Girdauskas E, Ikonomidis JS, Khoynezhad A, Siu SC, Verma S, Hope MD, Cameron DE, Hammer DF, Coselli JS, Moon MR, Sundt TM, Barker AJ, Markl M, Della Corte A, Michelena HI, Elefteriades JA. The American Association for Thoracic Surgery consensus guidelines on bicuspid aortic valve-related aortopathy: Full online-only version. J Thorac Cardiovasc Surg 2018;156:e41-74.

9. Gagné-Loranger M, Dumont É, Voisine P, Mohammadi S, Dagenais F. Natural history of 40-50 mm root/ascending aortic aneurysms in the current era of dedicated thoracic aortic clinics. Eur J Cardiothorac Surg 2016;50:562-6.

10. Howard DP, Banerjee A, Fairhead JF, Perkins J, Silver LE, Rothwell PM; Oxford Vascular Study. Population-based study of incidence and outcome of acute aortic dissection and premorbid risk factor control: 10-year results from the Oxford Vascular Study. Circulation 2013;127:2031-7.

11. Mendoza DD, Kochar M, Devereux RB, Basson CT, Min JK, Holmes K, Dietz HC, Milewicz DM, LeMaire SA, Pyeritz RE, Bavaria JE, Maslen CL, Song H, Kroner BL, Eagle KA, Weinsaft JW; GenTAC (National Registry of Genetically Triggered Thoracic Aortic Aneurysms and Cardiovascular Conditions) Study Investigators. Impact of image analysis methodology on diagnostic and surgical classification of patients with thoracic aortic aneurysms. 
Ann Thorac Surg 2011;92:904-12.

12. Du Bois D, Du Bois EF. A formula to estimate the approximate surface area if height and weight be known. 1916. Nutrition 1989;5:303-11; discussion 312-3.

13. Whelton PK, Carey RM, Aronow WS, Casey DE Jr, Collins KJ, Dennison Himmelfarb C, et al. 2017 ACC/ AHA/AAPA/ABC/ACPM/AGS/APhA/ASH/ASPC/ NMA/PCNA Guideline for the Prevention, Detection, Evaluation, and Management of High Blood Pressure in Adults: A Report of the American College of Cardiology/ American Heart Association Task Force on Clinical Practice Guidelines. J Am Coll Cardiol 2018;71:e127-248.

14. Coady MA, Rizzo JA, Hammond GL, Mandapati D, Darr U, Kopf GS, Elefteriades JA. What is the appropriate size criterion for resection of thoracic aortic aneurysms? J Thorac Cardiovasc Surg 1997;113:476-91; discussion 489-91.

15. Davies RR, Goldstein LJ, Coady MA, Tittle SL, Rizzo JA, Kopf GS, Elefteriades JA. Yearly rupture or dissection rates for thoracic aortic aneurysms: simple prediction based on size. Ann Thorac Surg 2002;73:1727; discussion 27-8.

16. Andrus BW, O'Rourke DJ, Dacey LJ, Palac RT. Stability of ascending aortic dilatation following aortic valve replacement. Circulation 2003;108 Suppl 1:II295-9.

17. Davies RR, Kaple RK, Mandapati D, Gallo A, Botta DM Jr, Elefteriades JA, Coady MA. Natural history of ascending aortic aneurysms in the setting of an unreplaced bicuspid aortic valve. Ann Thorac Surg 2007;83:1338-44.

18. Guo MH, Appoo JJ, Saczkowski R, Smith HN, Ouzounian M, Gregory AJ, Herget EJ, Boodhwani M. Association of Mortality and Acute Aortic Events with Ascending Aortic Aneurysm: A Systematic Review and Meta-analysis. JAMA Netw Open 2018;1:e181281.

19. Kim JB, Spotnitz M, Lindsay ME, MacGillivray TE, Isselbacher EM, Sundt TM 3rd. Risk of Aortic Dissection in the Moderately Dilated Ascending Aorta. J Am Coll Cardiol 2016;68:1209-19.

20. Danyi P, Elefteriades JA, Jovin IS. Medical therapy of thoracic aortic aneurysms: are we there yet? Circulation 2011;124:1469-76.

Cite this article as: Gulati A, Leach J, Wang Z, Xuan Y, Hope MD, Saloner DA, Ge L, Tseng EE. Ascending thoracic aortic aneurysm growth is minimal at sizes that do not meet criteria for surgical repair. Quant Imaging Med Surg 2022;12(1):333-340. doi: 10.21037/qims-21-55
21. Shores J, Berger KR, Murphy EA, Pyeritz RE. Progression of aortic dilatation and the benefit of long-term betaadrenergic blockade in Marfan's syndrome. N Engl J Med 1994;330:1335-41.

22. Silverman DI, Burton KJ, Gray J, Bosner MS, Kouchoukos NT, Roman MJ, Boxer M, Devereux RB, Tsipouras P. Life expectancy in the Marfan syndrome. Am J Cardiol 1995;75:157-60.

23. Propanolol Aneurysm Trial Investigators. Propranolol for small abdominal aortic aneurysms: results of a randomized trial. J Vasc Surg 2002;35:72-9.

24. Gadowski GR, Pilcher DB, Ricci MA. Abdominal aortic aneurysm expansion rate: effect of size and beta-adrenergic blockade. J Vasc Surg 1994;19:727-31.

25. Mullen M, Jin XY, Child A, Stuart AG, Dodd M, AragonMartin JA, Gaze D, Kiotsekoglou A, Yuan L, Hu J, Foley C, Van Dyck L, Knight R, Clayton T, Swan L, Thomson JDR, Erdem G, Crossman D, Flather M; AIMS Investigators. Irbesartan in Marfan syndrome (AIMS): a double-blind, placebo-controlled randomised trial. Lancet 2019;394:2263-70.

26. Sato T, Arakawa M, Tashima Y, Tsuboi E, Burdon G, Trojan J, Koyano T, Youn YN, Penov K, Pedroza AJ, Shabazzi M, Palmon I, Nguyen MN, Connolly AJ, Yamaguchi A, Fischbein MP. Statins Reduce Thoracic Aortic Aneurysm Growth in Marfan Syndrome Mice via Inhibition of the Ras-Induced ERK (Extracellular SignalRegulated Kinase) Signaling Pathway. J Am Heart Assoc 2018;7:e008543.

27. McLarty AJ, Bishawi M, Yelika SB, Shroyer AL, Romeiser J. Surveillance of moderate-size aneurysms of the thoracic aorta. J Cardiothorac Surg 2015;10:17.

28. Wang Z, Flores N, Lum M, Wisneski AD, Xuan Y, Inman J, Hope MD, Saloner DA, Guccione JM, Ge L, Tseng EE. Wall stress analyses in patients with $\geq 5 \mathrm{~cm}$ versus $<5 \mathrm{~cm}$ ascending thoracic aortic aneurysm. J Thorac Cardiovasc Surg 2021;162:1452-9.

29. Martin C, Sun W, Elefteriades J. Patient-specific finite element analysis of ascending aorta aneurysms. Am J Physiol Heart Circ Physiol 2015;308:H1306-16. 